$$
\text { Mary Ann Lielest, Inc. Fo publishers }
$$

\title{
Role of the Microbiota in Colorectal Cancer: Updates on Microbial Associations and Therapeutic Implications
}

\author{
Olivia I. Coleman ${ }^{* \dagger}$ and Tiago Nunes ${ }^{\dagger}$
}

\begin{abstract}
Genetic, environmental, and dietary factors have been found to influence the development and progression of colorectal cancer (CRC). More recently, accumulating evidence associates the intestinal microbiota with the initiation and progression of this disease. While studies have shown that individuals with CRC display alterations in gut bacterial composition, it remains somewhat unclear whether such differences drive cancer development or whether they are a response to tumorigenesis. In this review, the authors assess new evidence linking the community structure or specific bacterial factors of the intestinal microbiota to CRC development and progression, with insights into therapeutic implications.
\end{abstract}

Keywords: colorectal cancer; intestinal microbiota; tumorigenesis

\section{Introduction}

Colorectal cancer (CRC) is one of the leading causes of death in the western society, being ranked third most lethal neoplasia in the United States in both men and women. ${ }^{1}$ In 2014, the American Cancer Society estimated that approximately 136,830 new cases of CRC will be diagnosed in the United States, with more than 50,000 Americans expected to die due to disease progression or complications. ${ }^{1,2}$ The lifetime cancerrelated costs are considerable and differ by cancer site, disease stage, age at diagnosis, and treatment phase. Considering direct healthcare costs, CRC is the second most important neoplasia with estimated expenses of more than $\$ 14$ billion. ${ }^{3,4}$

Most cases of CRC originate from epithelial cells of the colorectal mucosa, being identified by the formation of glandular structures and histologically classified as adenocarcinomas. ${ }^{5}$ The development of CRC can be didactically viewed as a systematic process with three main stages: initiation, promotion, and progression (Fig. 1). ${ }^{6}$ In the initiation process, either spontaneously or after exposure to carcinogenic initiators, normal cells go through early unrepaired changes in DNA sequence and structure, which ultimately lead to their transformation into neoplastic cells. ${ }^{6-8}$ In the promotion phase, mutated cells undergo clonal expansion, promoting atypical tissue growth and tumor formation. In the progression phase, malignant tumor transformation and expansion take place with the occurrence of additional mutations, epigenetic alterations, and genetic instability. ${ }^{7}$ Thus, CRC development results from a progressive loss of normal control mechanisms related to cellular growth and differentiation.

Owing to the fact that single mutations are not sufficient to trigger malignant transformation in the intestinal epithelium, ${ }^{7}$ an accumulation of multiple mutations in proto-oncogenes, tumor suppressor genes, and DNA repair genes is needed to complete the carcinogenesis process. Most genetic alterations are found in pathways related to Wnt- $\beta$-catenin signaling, tyrosine kinase receptors, TGF $\beta$ signaling, DNA mismatch repair, and genes linked to apoptotic pathways and cell

\footnotetext{
Chair of Nutrition and Immunology, ZIEL_Research Center for Nutrition and Food Sciences, Technical University of Munich, Freising, Germany.

These authors contributed equally to this work.

*Address correspondence to: Olivia Coleman, PhD, Chair of Nutrition and Immunology, ZIEL-Research Center for Nutrition and Food Sciences, Technical University of Munich, Freising 85354, Germany, E-mail: olivia.coleman@tum.de
}

(c) Olivia I. Coleman and Tiago Nunes 2016; Published by Mary Ann Liebert, Inc. This Open Access article is distributed under the terms of the Creative Commons License (http://creativecommons.org/licenses/by/4.0), which permits unrestricted use, distribution, and reproduction in any medium, provided the original work is properly credited. 


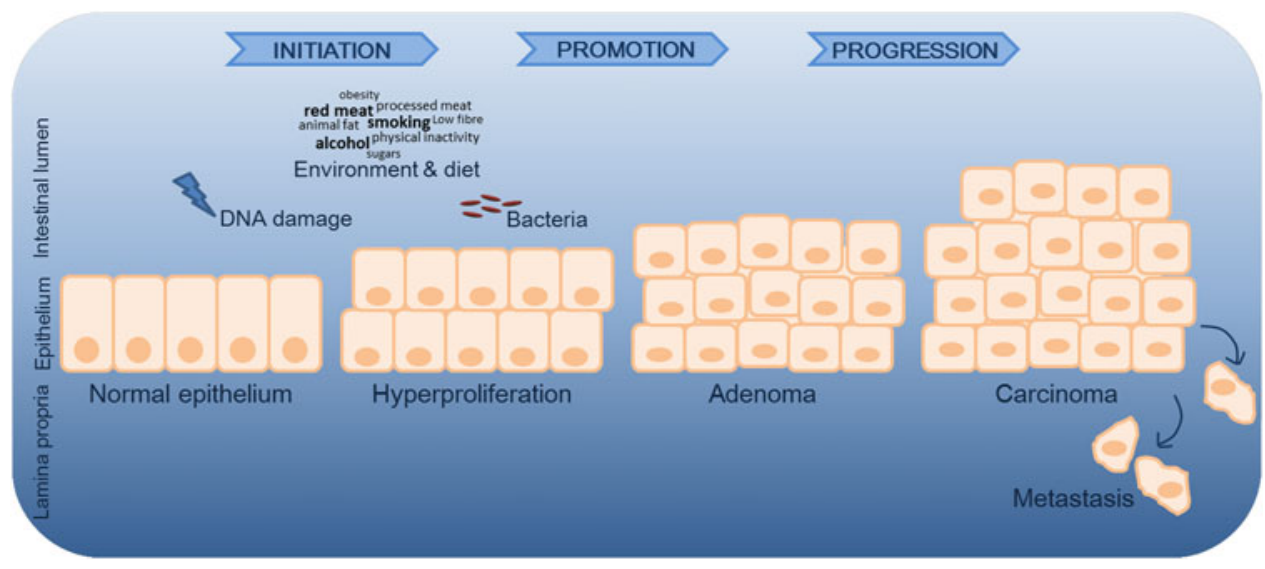

FIG. 1. Simplified representation of CRC progression. In the initiation process, normal cells go through early unrepaired changes in DNA sequence and structure, which ultimately lead to their transformation into neoplastic cells. ${ }^{6-8}$ In the promotion phase, mutated cells undergo clonal expansion, promoting atypical tissue growth and tumor formation. In addition to genetic mutations, environmental and microbial factors contribute to disease progression. Microbes may contribute by either promoting or suppressing CRC development, with bacteria being described as drivers and/or passengers of disease. ${ }^{58}$ In the progression phase, malignant tumor transformation and expansion take place. ${ }^{7} \mathrm{CRC}$, colorectal cancer.

cycle control. ${ }^{7}$ In addition to genetic alterations, the tumor microenvironment plays a critical role in CRC initiation and promotion, with the dietary intake and the intestinal microbiota being the most dominant factors of the luminal microenvironment in the gut. It has therefore been suggested that differences in diet and in the intestinal microbiota might be accountable for variations in CRC prevalence between two similar human populations. As an example, CRC is extremely rare in Native Africans, but considerably prevalent in African Americans $(<1$ case per 100,000 population vs. 65 per 100,000 population). ${ }^{9}$ In these populations, O'Keefe et al. showed that a larger consumption of animal products and an increased colonic population of toxic hydrogen and secondary bile salt-producing bacteria among African Americans were associated with increased CRC rates, supporting the hypothesis that CRC risk is affected by the interplay between diet and the intestinal microbiota. ${ }^{9}$ This review discusses the current evidence covering the interactions between the intestinal microbiota and the host in the development and progression of CRC.

\section{Microbiota, Genotoxicity, and Immune Activation}

Viral and bacterial infections are known to facilitate carcinogenesis in certain organs. Prominent examples include viral hepatitis and hepatocellular carcinoma, ${ }^{10-12}$ as well as Helicobacter pylori infection and gastric adenocarcinoma. ${ }^{13-15}$ In the case of the hepatitis B virus (HBV), for instance, the infection can contribute to liver carcinogenesis through direct and indirect mechanisms: genomic instability due to HBV-DNA integration into the host genome, deregulation of proliferation control by viral regulatory proteins, and epigenetic alterations driven by viral compounds targeting the expression of tumor suppressor genes. ${ }^{11}$ The secretion of virulence factors by $H$. pylori causes oxidative stress, chronic inflammation, and host DNA damage, resulting in carcinoma development. ${ }^{16-18}$ While there is a well-established link between inflammation, carcinogenesis, and microbial products, the function of the microbiota in initiating and promoting CRC is not well understood. ${ }^{19}$

For each cancer-associated infection, microorganisms can trigger common and etiology-specific carcinogenic pathways, having both direct and indirect neoplastic effects that go beyond the immune activation and the development of chronic inflammation (Fig. 2). Enterococcus faecalis, for instance, is known to produce extracellular superoxide that can induce chromosomal instability in human cells. ${ }^{19,20}$ In this regard, Wang et al. have shown that $E$. faecalis can activate DNA damage pathways, produce G2 arrest, and promote missegregation of chromosomes leading to aneuploidy and 


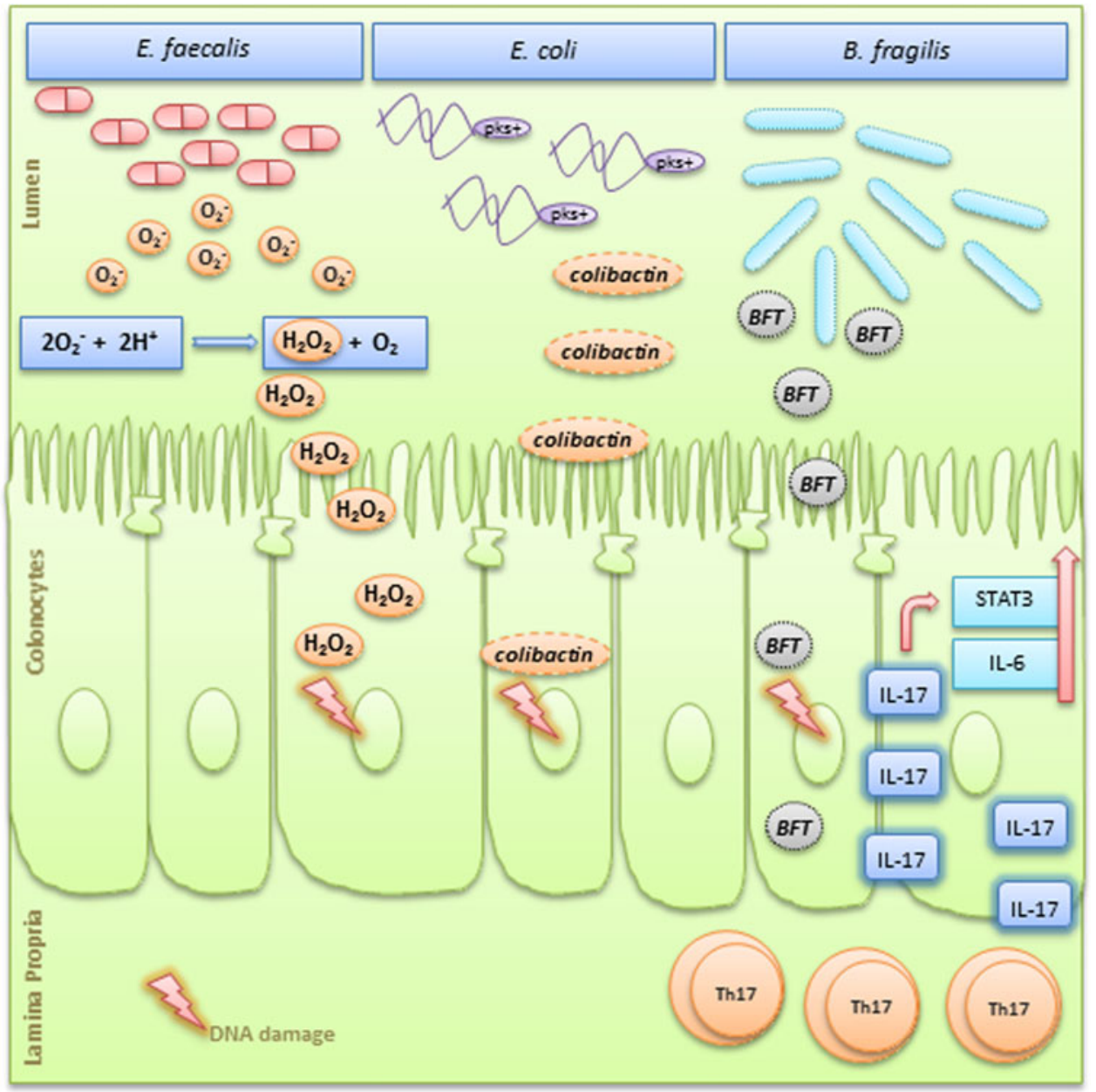

FIG. 2. Simplified graphic showing three different microorganisms and their pro-tumorigenesis mechanisms. Enterococcus faecalis produces extracellular superoxide $\left(\mathrm{O}_{2}{ }^{-}\right)$near the oxygenated luminal surface of colonic epithelial cells. In this acidic microenvironment, $\mathrm{O}_{2}{ }^{-}$production spontaneously generates $\mathrm{H}_{2} \mathrm{O}_{2}$ that diffuses into the epithelium and forms hydroxyl radicals at DNA sites, leading to DNA-protein crosslinks, DNA breaks, and base modifications. ${ }^{41}$ Escherichia coli of the phylogenetic group B2 carry a conserved genomic island named "pks," which allows the production of a genotoxin named colibactin. Colibactin can induce DNA double-strand breaks leading to chromosomal aberrations and increased frequency of gene mutations. ${ }^{22}$ ETBF is a subtype characterized by the secretion of a metalloprotease enterotoxin known as BFT. BFT is directly genotoxic to colonic epithelial cells and also stimulates cleavage of E-cadherin causing cell proliferation and breakage of the intestinal barrier. ${ }^{58} \mathrm{BFT}$ can also induce a persistent TH17-type inflammatory response with increased IL-17 expression and upregulation of STAT3 and IL-6, which have pro-proliferative and antiapoptotic properties. ${ }^{58}$ BFT, Bacteroides fragilis toxin; ETBF, enterotoxigenic Bacteroides fragilis.

tetraploidy in colonic epithelial cells in vitro. ${ }^{19}$ In vivo studies have confirmed this potential neoplastic influence, demonstrating that gnotobiotic IL-10-deficient mice colonized with E. faecalis, developed colitisassociated rectal dysplasia and adenocarcinoma. ${ }^{21}$ Another example is the Escherichia coli of the phyloge- netic group B2, which can produce the genotoxin named colibactin. ${ }^{22,23}$ Infection experiments with these strains induce DNA double-strand breaks in intestinal epithelial cells leading to mitotic and chromosomal aberrations together with an increased frequency of gene mutations and anchorage-independent 
growth. ${ }^{22}$ Importantly, Buc et al. showed a higher prevalence of colibactin-producing E. coli in biopsies of patients with CRC compared with those of patients with diverticulosis. ${ }^{24}$ An additional microorganism found to be associated with CRC is the Enterotoxigenic Bacteroides fragilis (ETBF), a subtype characterized by the secretion of a $20-\mathrm{kDa}$ metalloprotease enterotoxin known as $B$. fragilis toxin (BFT). ${ }^{25}$ When intestinal epithelial cell lines are exposed to this enterotoxin, cell adhesion molecules are cleaved, stress response and cytokine signaling pathways are activated, and an increased cellular proliferation, mediated by elevated expression of the c-Myc oncogene, takes place. ${ }^{25}$

Away from direct genotoxic capabilities, bacteria can also participate in tumorigenesis by promoting chronic unresolved inflammation. In this regard, epithelial barrier disruption and subsequent immune recognition of bacterial factors can lead to inflammationdriven neoplastic formation. ${ }^{26}$ Different bacterial species can initiate immune-mediated inflammation with characteristic kinetics and anatomic distribution. ${ }^{27}$ The importance of bacteria in inflammation-driven tumorigenesis is stressed by the decreased tumor formation found in several CRC mouse models housed in germ-free conditions or under antibiotic treatment. Accordingly, the inhibition of microbial recognition through the loss of pattern recognition receptor signaling or $\mathrm{T}$ helper cell activation leads to a diminished neoplastic transformation. ${ }^{26,28-30}$ In this regard, the knockout of the adapter MyD88, which participates in the downstream signaling of toll-like receptors, was shown to inhibit tumorigenesis in both $\mathrm{Apc}^{\mathrm{Min} /+}$ mice $^{29}$ and azoxymethane (AOM)-2\% dextran sodium sulfate (DSS)-induced models. ${ }^{28,30}$ Importantly, not only the absence of bacteria can lead to decreased neoplastic transformation, but superimposed colonic infection can also enhance intestinal tumorigenesis in $\mathrm{Apc}^{\mathrm{Min} /+}$ mice. ${ }^{31-33}$

In animal models with colitis-associated CRC, the resulting inflammatory microenvironment leads to elevated levels of reactive oxygen species (ROS) and prolonged immune activation, which may result in tissue damage, stimulation of oncogenes, and downregulation of tumor suppressor genes. ${ }^{25}$ However, the exact mechanisms by which inflammation promotes carcinogenesis are still poorly understood. Animal studies support the relevance of nuclear factor $-\kappa \mathrm{B}(\mathrm{NF}-\kappa \mathrm{B})$ signaling in inflammation-driven carcinogenesis and the importance of IL-6 in this context. ${ }^{26,34-37}$ IL-6 induces STAT3-mediated signal transduction affecting prolifer- ative, antiapoptotic, and proangiogenic genes. ${ }^{26,38-40}$ Elevated levels of ROS might also play an important role in bacteria-driven carcinogenesis as enteric bacteria have been shown to induce ROS, and mice lacking enzymes that protect against free radicals, such as glutathione peroxidases $\mathrm{Gpx}-1$ and $\mathrm{Gpx}-2$, are more susceptible to intestinal inflammation and tumorigenesis. $^{25,33,41}$ In the case of $H$. pylori and B. fragilis infection of stomach and intestine, respectively, the main source of ROS production is associated with the polyamine catabolic enzyme spermine oxidase (SMO) generating $\mathrm{H}_{2} \mathrm{O}_{2}$ from the conversion of spermine to spermidine. $^{25}$ SMO is promptly induced by these bacteria leading to SMO-dependent ROS production and DNA damage. ${ }^{25}$

Chronic innate inflammatory responses are often associated with tumorigenesis while adaptive immunity might inhibit the process. ${ }^{26} \mathrm{~T}$ cells are often linked to antitumor responses as more colonic tumor development is increased in Rag-/- mice and in animal models with defective interferon signaling, ${ }^{26,42-44}$ supporting the hypothesis that $\mathrm{T}$ cell-driven immunity is linked to tumor protective responses. Lymphocytedriven immune responses, although not absolutely required, have a critical role in regulating bacteriainduced intestinal inflammation and this inflammatory response may influence the progression of CRC. ${ }^{42}$ Erdman et al. showed that Helicobacter hepaticus-infected Rag-2-deficient mice developed colitis-associated carcinoma, whereas uninfected mice did not. ${ }^{42}$ In addition, adoptive transfer of $\mathrm{CD} 4^{+} \mathrm{CD} 45 \mathrm{RB}^{\text {lo }} \mathrm{CD} 25^{+} \mathrm{T}$ cells significantly inhibited colitis and cancer in this model, indicating that lymphocytes may be able to inhibit bacteria-induced inflammation and tumor formation. ${ }^{42}$ Several studies, however, have shown that $\mathrm{T}$ helper cell subsets have a differential role in cancer development. In this context, TH1 immunity is involved in antineoplastic responses, whereas TH17 contributes to tumorigenic responses. ${ }^{26,43,44}$ In this regard, $\mathrm{Wu}$ et al. have shown that ETBF colonizes $\mathrm{Apc}^{\mathrm{Min} /+}$ mice associated with the activation of STAT3 and TH17 responses leading to increased colonic tumor development in these animals. ${ }^{26}$

It is also important to point out that instead of having direct proneoplastic effects in the colon, chronic inflammation might work indirectly by targeting the intestinal microbiota to promote the expansion of microbes with genotoxic capacities. ${ }^{23}$ In line with this, Arthur et al. showed that inflamed IL-10-deficient mice exhibited a 100 -fold increase in the E. coli community, 
and that colibactin-producing E. coli induced increased tumor multiplicity without altering the level of inflammation compared with nongenotoxic strains in monoassociation studies. ${ }^{23}$ These data suggest that inflammation per se might not be the main contributing factor in tumor formation and that inflammation-driven selection of genotoxic bacteria within the complex community of the intestinal microbiota may link colonic inflammation and CRC development.

\section{The Microbiota and CRC in Human Studies}

Individuals with CRC display instability in the composition of their gut bacterial communities when compared with healthy controls (Table 1). However, these studies neither answer the cause or consequence question of dysbiosis in CRC, nor do they provide mechanistic insights by which the intestinal microbiota influences the development of CRC. Evidence for the association of human intestinal bacteria with CRC has stemmed from deep-sequencing technology, to date, provided by three independent studies that investigated microbial composition in healthy (off-tumor site) and late-stage CRC (on-tumor site) tissue. ${ }^{45-47}$ An enrichment of Fusobacterium nucleatum has been shown in CRC tissue, with a larger amount of F. nucleatum being associated with high degrees of microsatel-

Table 1. Microbiota Bacteria Associated with Colorectal Cancer in Human Subjects

\begin{tabular}{|c|c|c|}
\hline Bacteria & Association & References \\
\hline Fusobacterium & $\begin{array}{l}\text { Enriched in human colon } \\
\text { carcinoma }\end{array}$ & $45-47,50,87,88$ \\
\hline Streptococcus bovis & $\begin{array}{l}\text { Increased prevalence in } \\
\text { patients with carcinoma } \\
\text { of the colon }\end{array}$ & 89 \\
\hline Clostridium septicum & $\begin{array}{l}\text { Aortic infections associated } \\
\text { with colonic } \\
\text { adenocarcinoma/polyps }\end{array}$ & 90 \\
\hline Slackia & $\begin{array}{l}\text { Overrepresented in tissue } \\
\text { of CRC patients }\end{array}$ & 45 \\
\hline Collinsella & $\begin{array}{l}\text { Overrepresented in tissue } \\
\text { of CRC patients }\end{array}$ & 45 \\
\hline Roseburia & $\begin{array}{l}\text { Overrepresented in tissue } \\
\text { of CRC patients }\end{array}$ & 45 \\
\hline Faecalibacterium & $\begin{array}{l}\text { Overrepresented in tissue } \\
\text { of CRC patients }\end{array}$ & 45 \\
\hline Bacteroides fragilis & $\begin{array}{l}\text { Increased prevalence of } \\
\text { ETBF in colon cancer } \\
\text { patients }\end{array}$ & 50,91 \\
\hline Enterococcus faecalis & $\begin{array}{l}\text { Significantly higher } \\
\text { populations in colorectal } \\
\text { cancer patients }\end{array}$ & 92 \\
\hline Escherichia coli & $\begin{array}{l}\text { Enhanced adhesion and } \\
\text { invasion in colorectal } \\
\text { cancer tumors }\end{array}$ & $23,24,93,94$ \\
\hline
\end{tabular}

CRC, colorectal cancer; ETBF, enterotoxigenic Bacteroides fragilis. lite instability (MSI-high) and CpG island methylator phenotype (CIMP). ${ }^{46-48}$ Furthermore, F. nucleatum in colorectal carcinoma tissue was shown to be inversely proportional to the $\mathrm{CD} 3^{+} \mathrm{T}$ cell density, providing mechanistic evidence for the interactive roles of this microorganism in adaptive immunity, ${ }^{49}$ an important insight for the targeting of the microbiota and immunity in CRC prevention and therapy. A further validation for the connection between $F$. nucleatum and colon cancer, with a correlation to inflammatory factors, was provided by Wei et al. ${ }^{50}$ The same study also first reported a patient prognosis value of $B$. fragilis and Fusobacterium prausnitzii through the induction of intestinal inflammation, suggesting all three microorganisms as potential prognostic biomarkers for CRC.

The first high-resolution map of the colonic microbiota associated with human CRC showed that Coriobacteria were overrepresented, whereas potentially pathogenic Enterobacteria were underrepresented in patients. ${ }^{45}$ First experiments using Denaturing Gradient Gel Electrophoresis and Ribosomal Intergenic Spacer Analysis fingerprinting, indicated striking differences in microbial communities between tumor and off-tumor tissue. Subsequent FLX 454 titanium pyrosequencing revealed significantly altered community structures of the microbiota related to tumor vs. off-tumor sites at higher resolution. In these studies, CRC was consistently associated with overrepresentation of Coriobacteridae, especially of the genera Slackia and Collinsella, and underrepresentation of Citrobacter, Shigella, Cronobacter, Kluyvera, Serratia, and Salmonella spp. of the Enterobacteriaceae family. Shifts in microbial composition are often the result of dramatic physiological and metabolic alterations in the colonic microenvironment during tumorigenesis; these changes seem to benefit the rise of tumor-associated commensal-like bacteria with subsequent underrepresentation of Enterobacteria that might be linked to CRC pathogenesis. ${ }^{51,52}$ Some of these tumor-associated bacteria are major butyrate-producing microorganisms with potentially protective functions in CRC. In this regard, butyrate induces cell cycle arrest and increased apoptosis of cancer cells, ${ }^{53}$ but also serves as an energy source for neoplastic colonocytes.

\section{The Microbiota and CRC in Animal Models}

Studies addressing the role of the gut microbial ecosystem in CRC development using animal models are compiled in Table 2. The characterization of the gut microbiota in a murine model of AOM DSS-induced 
Table 2. Microbiota Bacteria Associated with Colorectal Cancer in Murine Models

\begin{tabular}{|c|c|c|}
\hline Bacteria & Association & References \\
\hline Bacteroides fragilis & $\begin{array}{l}\text { Enterotoxigenic } B \text {. fragilis (ETBF) augments spontaneous colon cancer in multiple intestinal } \\
\text { neoplasia (Min) mice }\end{array}$ & 26,91 \\
\hline Bacteroides vulgatus & Monoassociation of $\mathrm{AOM}-\mathrm{IL} 10^{-1-}$ mice caused mild colorectal tumorigenesis & 30 \\
\hline Bifidobacterium longum & $\begin{array}{l}\text { Decreased the incidence of AOM-induced large aberrant crypt foci, which are predictive of } \\
\text { tumor incidence, and IQ-induced colon tumors and multiplicity }\end{array}$ & 73,81 \\
\hline $\begin{array}{l}\text { Citrobacter rodentium \& } \\
\quad \text { Citrobacter freundii }\end{array}$ & $\begin{array}{l}\text { Induces colonic crypt hyperplasia and increases the susceptibility to neoplastic transformation } \\
\text { in mice; reduces latent period for appearance of 1,2-dimethylhydrazine (DMH) tumors }\end{array}$ & 31,92 \\
\hline Enterococcus faecalis & Triggers adenocarcinoma in IL-10 KO mice & 21,93 \\
\hline Escherichia coli & $\begin{array}{l}\text { E. coli NC101 promotes invasive carcinoma in AOM-IL } 10^{-1-} \text { mice; E. coli } 11 \mathrm{G} 5 \text { increases colonic } \\
\text { polyps in multiple intestinal neoplasia (Min) mice. }\end{array}$ & $23,94,95$ \\
\hline Helicobacter hepaticus & $\begin{array}{l}\text { Promotes colon tumorigenesis in the BALB-RagMin (C.Cg-Rag2 }{ }^{-1-} \mathrm{ApcMin}^{-1-} \text { ) mouse, and in } \\
\text { the Smad } 3^{-/-} \text {mouse }\end{array}$ & 96,97 \\
\hline $\begin{array}{l}\text { H. hepaticus \& Helicobacter } \\
\text { bilis }\end{array}$ & Induction of colon cancer through dual infection in $\mathrm{Mdr} \mathrm{a}^{-1-}$ mice & 97 \\
\hline $\begin{array}{l}\text { Helicobacter typhlonius \& } \\
\text { Helicobacter rodentium }\end{array}$ & Coinfection increases incidence of inflammation-associated colon neoplasia in IL $10^{-/-}$mice & 98 \\
\hline
\end{tabular}

CRC has shown an enrichment in operational taxonomic units (OTUs) affiliated with members of the genera Bacteroides, Odoribacter, and Akkermansia, whereas OTUs affiliated with members of the Prevotellaceae and Porphyromonadaceae families were decreased. ${ }^{54}$ Furthermore, the administration of antibiotics in this model resulted in a drastic reduction in tumor size and number, implying that changes in the microbiota directly contribute to tumorigenesis. ${ }^{54}$ In contrast to conventionally raised mice, germ-free glutathione peroxidase double knockout (GPX-DKO) mice as well as interleukin-10-deficient (IL10 ${ }^{-/-}$) mice, treated with AOM, display normal colon histology and no tumor development. ${ }^{30,33}$ Furthermore, in the Apc $\mathrm{Ain}^{\mathrm{n} /+}$ murine model of colon carcinogenesis, germ-free housing showed a reduction in tumor burden, and the introduction of $B$. fragilis or $F$. nucleatum increased carcinogenesis. ${ }^{26,55,56}$ These results provide in vivo evidence for the influence of bacteria on carcinogenesis.

Nucleotide-binding oligomerization domain-containing protein 2 (NOD2) is a cytoplasmic pattern recognition receptor that is linked to the development of Crohn's disease in humans. Dysbiotic microbiota in NOD2 $2^{-1-}$ mice contributed to the development of colitis and colitis-associated cancer (CAC) ${ }^{57}$ In addition, disease risk was ameliorated in $\mathrm{NOD}^{-/-}$mice after the treatment with antibiotics or anti-IL-6 receptor-neutralizing antibodies. Most interestingly, the transfer of dysbiotic microbiota into germ-free wild-type (WT) mice again caused the development of colitis and CAC. Likewise, transplanting the normal microbiota from WT mice into NOD2 ${ }^{-1-}$ mice reduced disease risk. ${ }^{57}$ These findings exemplify a role of microbial communities in inflammation and carcinogenesis. Furthermore, these observations propose that the manipulation of a dysbiotic microbiota could offer a possible therapeutic approach in the treatment of CRC and other human intestinal diseases.

\section{The Bacterial Driver-Passenger Model}

In light of potentially distinct functions of bacterial groups in colonic tumorigenesis, a bacterial driverpassenger model for CRC was proposed. ${ }^{58}$ Bacterial drivers are defined as intestinal bacteria with procarcinogenic features that may initiate CRC development. For instance, a pro-carcinogenic feature of particular E. coli strains, harboring the genotoxin colibactin, can induce single-strand DNA breaks, and thereby increase the mutation rate of infected cells. ${ }^{22}$ Another bacterial CRC driver was identified in a mouse model of ETBF-induced colitis and carcinogenesis. In this model, ETBF can enhance tumorigenesis, possibly through the induction of a persistent TH17type inflammatory response, causing DNA damage and genetic instability in human cells. ${ }^{26,59}$ In humans, potentially pathogenic Enterobacteria, such as Shigella spp., are rare in healthy individuals, but are overrepresented in nonmalignant colonic mucosa of patients with adenomas. ${ }^{60,61}$ This finding supports the early CRC-stage association of such species with the intestinal mucosa, suggesting a role for bacterial drivers.

In contrast, intestinal bacterial passengers constitute relatively poor colonizers of a healthy colon that have a competitive advantage in the tumor microenvironment and, therefore, outcompete bacterial drivers of CRC. For example, the distorted colon wall structure in a tumor microenvironment may expose the collagen fibers in the basement membrane, allowing access to 
bacteria such as S. gallolyticus subsp. gallolyticus. ${ }^{62}$ Accordingly, the prevalence of $S$. gallolyticus subsp. gallolyticus in the general population is much lower than that found in patients with colonic adenomas and CRC samples, ${ }^{45-47,63}$ suggesting that these microorganisms represent bacterial passengers. Another example of potential bacterial passengers are the Fusobacterium spp., which are found consistently overrepresented in tumor samples ${ }^{45-47}$ with no clear role in CRC development and progression. This would support the idea for a role of Fusobacterium spp. as passenger bacteria.

While the driver-passenger model does not exclude passenger bacteria as active culprits of tumor progression, it rather suggests that their involvement may be in later disease stages. Nevertheless, the composition of the indigenous rather than the tumor microbiota of patients with CRC would be a more relevant indicator for the risk of developing colon cancer. An increased understanding of shifts in the microbiota would enable the identification of bacterial drivers of colon cancer and thereby provide an invaluable tool for early diagnosis of colon cancer and new prevention strategies.

\section{Therapeutic Implications}

Taking into consideration that microbe-host interactions contribute to tumorigenesis, several different strategies have been evaluated in the context of CRC prevention. In this regard, bacteria-induced ROS production and its consequent DNA damage is one possible target for antineoplastic chemoprevention in CRC. Treatment with an inhibitor of polyamine catabolism has been shown to decrease proliferation and tumorigenesis in ETBF-induced mouse models and $\mathrm{Apc}^{\mathrm{Min} /+}$ rodents. ${ }^{25}$ Another mechanism by which the colonic microbiota might have a role in CRC antineoplastic strategies relies on microbial fermentation products. Butyrate, a short-chain fatty acid (SCFA) produced during microbial fermentation of indigestible complex carbohydrates such as fiber, for instance, initiates growth arrest and apoptosis of colonic epithelial cells in vitro. ${ }^{64}$ SCFA might not only have antineoplastic functions, but also an important anti-inflammatory role, targeting G-protein-coupled receptor 43 (GPR43). ${ }^{65}$

Several studies have highlighted the importance of the microbiota composition in the tumor patient response to chemotherapy or checkpoint blockade immunotherapy. ${ }^{66,67}$ Of importance here are findings of Sivan et al. (2015) and Vétizou et al. (2015), demon- strating that constituents of the intestinal microbiota can influence the outcome of tumor immunotherapy through the augmentation of dendritic cell activation and subsequent priming of antitumor $\mathrm{T}$ cell responses. ${ }^{68,69}$ In light of the heterogeneous antitumor immunity of patients, the identification of microbes that may serve as biomarkers for predicting therapeutic responses as well as maximizing the benefit of clinical cancer immunotherapy, is an obvious growing field of research.

Mechanistically, microbes may promote carcinogenesis by different processes, such as toxic metabolite production and genotoxic biosynthesis, ${ }^{70}$ providing a further CRC treatment approach. A recent study aimed at inhibiting toxic effects of colibactin toxinproducing E. coli, which represent frequent colonizers of CRCs. Two boronic acid-based compounds were identified, which were shown to bind to the active site of the ClbP enzyme involved in the synthesis of colibactin, and shown to suppress DNA damage and tumorigenesis induced by $p k s$-harboring bacteria. ${ }^{71}$ While confirming the importance of colibactin toxinproducing E. coli in colon tumorigenesis, this study also provides a novel family of inhibitors to target pks-harboring bacteria in the treatment of CRC.

The consumption of lactic acid bacteria, together with some dietary factors, such as fibers and cruciferous vegetables, has been found to be inversely correlated with the incidence of CRC in humans. ${ }^{72}$ These bacteria have been found to inhibit cancer development in culture $\mathrm{e}^{73-76}$ and in animal models of CRC. ${ }^{77-81} \mathrm{In}$ the case of the mutagenic compounds known as heterocyclic amines (HCAs), lactic acid-producing bacteria can prevent HCA-related induction of DNA damage by direct binding to these amines through the components of their cell wall. ${ }^{72}$ The presence of this specific population of bacteria can be enhanced by their direct ingestion (probiotics), usually in fermented dairy products, or by the consumption of nondigestible oligosaccharides (prebiotics), which can act as specific substrates for lactobacilli and Bifidobacteria. ${ }^{73}$ Importantly, two of these nondigestible prebiotics, lactulose and inulin, have also been shown to decrease the level of carcinogen-induced DNA damage in the colon of rodents. ${ }^{73,82}$ The modulation of the gut microbiota by probiotics and prebiotics may positively impact on the crosstalk between the immune system and the microbiota. Preclinical models provide evidence that the administration of probiotics has protective effects against CRC by antineoplastic and antiproliferative 
activities, reduction in aberrant crypt foci, SCFA formation, downregulation of proinflammatory cytokines, inhibition of pathogens and cancer-causing microbes, immunostimulation, and reduction of pro-carcinogenic enzymatic activity. ${ }^{83}$

\section{Conclusion}

In animal models, environmental and dietary factors, including the intestinal microbiota, seem to play a critical role in the early stages of CRC formation. Even though no direct link between the colonic microbiota and the initiation of intestinal tumorigenesis in humans has yet been established, a growing body of evidence suggests that the selection of genotoxic bacteria might play an important role in CRC initiation and promotion. Alterations in the microbiota composition and function that were thought to be a passive reaction to changes in the microenvironment might in fact be an active contributing factor to the development of CRC. The notion of a causal link between dysbiosis and CRC opens a field of microbial genes as potential biomarkers for CRC. ${ }^{84-86} \mathrm{An}$ increased understanding of bacterial community shifts taking place in the context of CRC, will allow for future therapeutic and preventive strategies, based on intestinal microbiota modulation and microbe-host interactions, which may form a crucial part of the armamentarium against this lethal type of cancer.

\section{Funding}

This work was supported by the German Research Foundation (DFG) and the Technische Universität München within the Open Access Publishing Funding Program.

\section{Author Contributions}

All authors listed, have made substantial, direct, and intellectual contribution to the work, and approved it for publication.

\section{Author Disclosure Statement}

The authors declare that the research was conducted in the absence of any commercial or financial relationships that could be construed as a potential conflict of interest.

\section{References}

1. Siegel R, Desantis C, Jemal A. Colorectal cancer statistics, 2014. Cancer J Clin. 2014;64:104-117.

2. Siegel R, Ma J, Zou Z, et al. Cancer statistics, 2014. Cancer J Clin. 2014;64:9-29.
3. Mariotto AB, Yabroff KR, Shao Y, et al. Projections of the cost of cancer care in the United States: 2010-2020. J Natl Cancer Inst. 2011;103:117128.

4. Lang K, Lines LM, Lee DW, et al. Lifetime and treatment-phase costs associated with colorectal cancer: evidence from SEER-Medicare data. Clin Gastroenterol Hepatol. 2009;7:198-204.

5. Fleming M, Ravula S, Tatishchev SF, et al. Colorectal carcinoma: pathologic aspects. J Gastrointest Oncol. 2012;3:153-173.

6. Ponz de Leon M, Percesepe A. Pathogenesis of colorectal cancer. Digest Liver Dis. 2000;32:807-821.

7. Centelles JJ. General aspects of colorectal cancer. ISRN Oncol. 2012;2012:139268.

8. Jass JR. Pathogenesis of colorectal cancer. Surg Clin North Am. 2002;82:891-904.

9. O'Keefe SJD, Chung D, Mahmoud N, et al. Why do African Americans get more colon cancer than native Africans? J Nutr. 2007;137:175s-182s.

10. Levrero M. Viral hepatitis and liver cancer: the case of hepatitis. C Oncogene 2006;25:3834-3847.

11. Guerrieri F, Belloni L, Pediconi N, et al. Molecular mechanisms of HBV-associated hepatocarcinogenesis. Semin Liver Dis. 2013;33:147-156.

12. McMahon BJ. Chronic hepatitis B virus infection. Med Clin North Am. 2014;98:39-54.

13. Parsonnet J, Friedman GD, Vandersteen DP, et al. Helicobacter pylori infection and the risk of gastric carcinoma. N Engl J Med. 1991;325 1127-1131.

14. Stolte M, Meining A. Helicobacter pylori and Gastric Cancer. Oncologist. 1998:3:124-128

15. Wroblewski LE, Peek RM, Jr., Wilson KT. Helicobacter pylori and gastric cancer: factors that modulate disease risk. Clin Microbiol Rev. 2010;23:713-739.

16. Hardbower DM, de Sablet T, Chaturvedi R, et al. Chronic inflammation and oxidative stress: the smoking gun for Helicobacter pylori-induced gastric cancer? Gut Microbes. 2013;4:475-481.

17. Koeppel M, Garcia-Alcalde F, Glowinski F, et al. Helicobacter pylori infection causes characteristic DNA damage patterns in human cells. Cell Rep. 2015;11:1703-1713.

18. Wroblewski LE, Peek RM, Jr. Helicobacter pylori in gastric carcinogenesis: mechanisms. Gastroenterol Clin North Am. 2013;42:285-298.

19. Wang X, Allen TD, May RJ, et al. Enterococcus faecalis induces aneuploidy and tetraploidy in colonic epithelial cells through a bystander effect. Cancer Res. 2008:68:9909-9917.

20. Wang X, Huycke MM. Extracellular superoxide production by Enterococcus faecalis promotes chromosomal instability in mammalian cells. Gastroenterology. 2007;132:551-561.

21. Balish E, Warner T. Enterococcus faecalis induces inflammatory bowel disease in interleukin-10 knockout mice. Am J Pathol. 2002;160:22532257.

22. Cuevas-Ramos G, Petit CR, Marcq I, et al. Escherichia coli induces DNA damage in vivo and triggers genomic instability in mammalian cells. Proc Natl Acad Sci U S A. 2010;107:11537-11542.

23. Arthur JC, Perez-Chanona E, Muhlbauer M, et al. Intestinal inflammation targets cancer-inducing activity of the microbiota. Science. 2012;338:120-123.

24. Buc E, Dubois D, Sauvanet $P$, et al. High prevalence of mucosa-associated E. coli producing cyclomodulin and genotoxin in colon cancer. PloS One. 2013;8:e56964.

25. Goodwin AC, Destefano Shields CE, Wu S, et al. Polyamine catabolism contributes to enterotoxigenic Bacteroides fragilis-induced colon tumorigenesis. Proc Natl Acad Sci U S A. 2011;108:15354-15359.

26. Wu S, Rhee KJ, Albesiano E, et al. A human colonic commensal promotes colon tumorigenesis via activation of $\mathrm{T}$ helper type $17 \mathrm{~T}$ cell responses. Nat Med. 2009;15:1016-1022.

27. Kim SC, Tonkonogy SL, Albright CA, et al. Variable phenotypes of enterocolitis in interleukin 10-deficient mice monoassociated with two different commensal bacteria. Gastroenterology. 2005;128:891-906.

28. Rakoff-Nahoum S, Medzhitov R. Regulation of spontaneous intestinal tumorigenesis through the adaptor protein MyD88. Science. 2007:317:124-127.

29. Su LK, Kinzler KW, Vogelstein B, et al. Multiple intestinal neoplasia caused by a mutation in the murine homolog of the APC gene. Science. 1992;256:668-670. 
30. Uronis JM, Muhlbauer $\mathrm{M}$, Herfarth $\mathrm{HH}$, et al. Modulation of the intestinal microbiota alters colitis-associated colorectal cancer susceptibility. PloS One. 2009;4:e6026.

31. Newman JV, Kosaka T, Sheppard BJ, et al. Bacterial infection promotes colon tumorigenesis in Apc(Min/+) mice. J Infect Dis. 2001;184:227-230.

32. Kado S, Uchida K, Funabashi H, et al. Intestinal microflora are necessary for development of spontaneous adenocarcinoma of the large intestine in T-cell receptor beta chain and p53 double-knockout mice. Cancer Res. 2001;61:2395-2398.

33. Chu FF, Esworthy RS, Chu PG, et al. Bacteria-induced intestinal cancer in mice with disrupted Gpx1 and Gpx2 genes. Cancer Res. 2004;64:962-968.

34. Greten FR, Eckmann L, Greten TF, et al. IKKbeta links inflammation and tumorigenesis in a mouse model of colitis-associated cancer. Cell. 2004;118:285-296.

35. Karin M, Greten FR. NF-kappaB: linking inflammation and immunity to cancer development and progression. Nat Rev Immunol. 2005;5:749-759.

36. Naugler WE, Sakurai T, Kim S, et al. Gender disparity in liver cancer due to sex differences in MyD88-dependent IL-6 production. Science. 2007;317:121-124.

37. Naugler WE, Karin M. The wolf in sheep's clothing: the role of interleukin- 6 in immunity, inflammation and cancer. Trends Mol Med. 2008;14:109119.

38. $\mathrm{Yu} \mathrm{H}$, Jove R. The STATs of cancer-new molecular targets come of age. Nature reviews. Cancer. 2004;4:97-105.

39. Yu H, Kortylewski M, Pardoll D. Crosstalk between cancer and immune cells: role of STAT3 in the tumour microenvironment. Nat Rev Immunol. 2007;7:41-51.

40. Kortylewski M, Yu H. Role of Stat3 in suppressing anti-tumor immunity. Curr Opin Immunol. 2008;20:228-233.

41. Huycke MM, Abrams V, Moore DR. Enterococcus faecalis produces extracellular superoxide and hydrogen peroxide that damages colonic epithelial cell DNA. Carcinogenesis. 2002;23:529-536.

42. Erdman SE, Poutahidis $T$, Tomczak $M$, et al. CD4+ CD25+ regulatory $T$ lymphocytes inhibit microbially induced colon cancer in Rag2-deficient mice. Am J Pathol. 2003;162:691-702.

43. Dunn GP, Koebel CM, Schreiber RD. Interferons, immunity and cancer immunoediting. Nat Rev Immunol. 2006;6:836-848.

44. Shankaran V, Ikeda H, Bruce AT, et al. IFNgamma and lymphocytes prevent primary tumour development and shape tumour immunogenicity. Nature. 2001;410:1107-1111.

45. Marchesi JR, Dutilh BE, Hall N, et al. Towards the human colorectal cancer microbiome. PloS One. 2011;6:e20447.

46. Kostic AD, Gevers D, Pedamallu CS, et al. Genomic analysis identifies association of Fusobacterium with colorectal carcinoma. Genome Res. 2012;22:292-298.

47. Castellarin M, Warren RL, Freeman JD, et al. Fusobacterium nucleatum infection is prevalent in human colorectal carcinoma. Genome Res. 2012;22:299-306.

48. Tahara T, Yamamoto E, Suzuki H, et al. Fusobacterium in colonic flora and molecular features of colorectal carcinoma. Cancer Res. 2014;74:13111318.

49. Mima K, Sukawa Y, Nishihara R, et al. Fusobacterium nucleatum and T Cells in Colorectal Carcinoma. JAMA Oncol. 2015;1:653-661.

50. Wei Z, Cao S, Liu S, et al. Could gut microbiota serve as prognostic biomarker associated with colorectal cancer patients' survival? A pilot study on relevant mechanism. Oncotarget. 2016;7:46158-46172.

51. Sansonetti PJ. War and peace at mucosal surfaces. Nat Rev Immunol. 2004;4:953-964.

52. Corfield AP, Myerscough N, Longman R, et al. Mucins and mucosal protection in the gastrointestinal tract: new prospects for mucins in the pathology of gastrointestinal disease. Gut. 2000;47:589-594.

53. Bordonaro M, Lazarova DL, Sartorelli AC. Butyrate and Wnt signaling: a possible solution to the puzzle of dietary fiber and colon cancer risk? Cell Cycle. 2008;7:1178-1183.

54. Zackular JP, Baxter NT, Iverson KD, et al. The gut microbiome modulates colon tumorigenesis. Mbio. 2013;4.

55. Kostic AD, Chun E, Robertson L, et al. Fusobacterium nucleatum potentiates intestinal tumorigenesis and modulates the tumor-immune microenvironment. Cell Host Microbe. 2013;14:207-215.

56. Li Y, Kundu P, Seow SW, et al. Gut microbiota accelerate tumor growth via c-jun and STAT3 phosphorylation in APCMin/+ mice. Carcinogenesis. 2012;33:1231-1238.
57. Couturier-Maillard A, Secher T, Rehman A, et al. NOD2-mediated dysbiosis predisposes mice to transmissible colitis and colorectal cancer. J Clin Invest. 2013;123:700-711.

58. Tjalsma $\mathrm{H}$, Boleij A, Marchesi JR, et al. A bacterial driver-passenger model for colorectal cancer: beyond the usual suspects. Nat Rev Microbiol. 2012;10:575-582.

59. Housseau F, Sears CL. Enterotoxigenic Bacteroides fragilis (ETBF)-mediated colitis in Min (Apc+/-) mice: a human commensal-based murine model of colon carcinogenesis. Cell Cycle. 2010;9:3-5.

60. Ahmed S, Macfarlane GT, Fite A, et al. Mucosa-associated bacterial diversity in relation to human terminal ileum and colonic biopsy samples. Appl Environ Microbiol. 2007;73:7435-7442.

61. Shen XJ, Rawls JF, Randall T, et al. Molecular characterization of mucosal adherent bacteria and associations with colorectal adenomas. Gut Microbes. 2010;1:138-147.

62. Boleij A, Muytjens CM, Bukhari SI, et al. Novel clues on the specific association of Streptococcus gallolyticus subsp gallolyticus with colorectal cancer. J Infect Dis. 2011;203:1101-1109.

63. Boleij A, van Gelder MM, Swinkels DW, et al. Clinical Importance of Streptococcus gallolyticus infection among colorectal cancer patients: systematic review and meta-analysis. Clin Infect Dis. 2011;53 870-878.

64. Heerdt BG, Houston MA, Augenlicht LH. Short-chain fatty acid-initiated cell cycle arrest and apoptosis of colonic epithelial cells is linked to mitochondrial function. Cell Growth Differ. 1997;8:523-532.

65. Maslowski KM, Vieira AT, Ng A, et al. Regulation of inflammatory responses by gut microbiota and chemoattractant receptor GPR43. Nature. 2009;461:1282-1286

66. Pitt JM, Vétizou $M$, Waldschmitt N, et al. Fine-Tuning Cancer Immunotherapy: optimizing the Gut Microbiome. Cancer Res. 2016;76:4602-4607.

67. West NR, Powrie F. Immunotherapy not working? check your microbiota Cancer Cell. 2015;28:687-689.

68. Sivan A, Corrales L, Hubert N, et al. Commensal Bifidobacterium promotes antitumor immunity and facilitates anti-PD-L1 efficacy. Science. 2015;350:1084-1089.

69. Vetizou M, Pitt JM, Daillere R, et al. Anticancer immunotherapy by CTLA-4 blockade relies on the gut microbiota. Science. 2015;350:1079-1084.

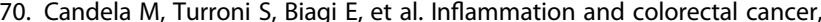
when microbiota-host mutualism breaks. World J Gastroenterol. 2014;20:908-922.

71. Cougnoux A, Delmas J, Gibold L, et al. Small-molecule inhibitors prevent the genotoxic and protumoural effects induced by colibactin-producing bacteria. Gut. 2016;65:278-285.

72. Zsivkovits M, Fekadu K, Sontag G, et al. Prevention of heterocyclic amineinduced DNA damage in colon and liver of rats by different lactobacillus strains. Carcinogenesis. 2003;24:1913-1918.

73. Rowland IR, Rumney CJ, Coutts JT, et al. Effect of Bifidobacterium longum and inulin on gut bacterial metabolism and carcinogen-induced aberrant crypt foci in rats. Carcinogenesis. 1998;19:281-285.

74. Pool-Zobel BL, Munzner R, Holzapfel WH. Antigenotoxic properties of lactic acid bacteria in the $\mathrm{S}$. typhimurium mutagenicity assay. Nutr Cancer. 1993;20:261-270.

75. Ayebo AD, Shahani KM, Dam R. Antitumor component(s) of yogurt: fractionation. J Dairy Sci. 1981;64:2318-2323.

76. Reddy GV, Shahani KM, Banerjee MR. Inhibitory effect of yogurt on Ehrlich Ascites tumor-cell proliferation. J Natl Cancer Inst. 1973;50:815-817.

77. Pool-Zobel BL, Bertram B, Knoll M, et al. Antigenotoxic properties of lactic acid bacteria in vivo in the gastrointestinal tract of rats. Nutr Cancer. 1993;20:271-281.

78. Pool-Zobel BL, Neudecker C, Domizlaff I, et al. Lactobacillus- and bifidobacterium-mediated antigenotoxicity in the colon of rats. Nutr Cancer. 1996;26:365-380.

79. Goldin BR, Gorbach SL. Effect of Lactobacillus acidophilus dietary supplements on 1,2-dimethylhydrazine dihydrochloride-induced intestinal cancer in rats. J Natl Cancer Inst. 1980;64:263-265.

80. Goldin BR, Gualtieri LJ, Moore RP. The effect of Lactobacillus GG on the initiation and promotion of $\mathrm{DMH}$-induced intestinal tumors in the rat. Nutr Cancer. 1996;25:197-204.

81. Reddy BS, Rivenson A. Inhibitory effect of Bifidobacterium longum on colon, mammary, and liver carcinogenesis induced by 2-amino-3methylimidazo[4,5-f]quinoline, a food mutagen. Cancer Res. 1993;53: 3914-3918. 
82. Rowland IR, Bearne CA, Fischer $R$, et al. The effect of lactulose on DNA damage induced by $\mathrm{DMH}$ in the colon of human flora-associated rats. Nutr Cancer. 1996;26:37-47.

83. Ambalam P, Raman M, Purama RK, et al. Probiotics, prebiotics and colorectal cancer prevention. Best Pract Res Clin Gastroenterol. 2016;30:119-131.

84. Zeller G, Tap J, Voigt AY, et al. Potential of fecal microbiota for early-stage detection of colorectal cancer. Mol Syst Biol. 2014;10:766.

85. Zackular JP, Rogers MA, Ruffin MTt, et al. The human gut microbiome as a screening tool for colorectal cancer. Cancer Prev Res. 2014;7:1112-1121.

86. Dejea CM, Wick EC, Hechenbleikner EM, et al. Microbiota organization is a distinct feature of proximal colorectal cancers. Proc Natl Acad Sci U S A. 2014;111:18321-18326.

87. Chen W, Liu F, Ling Z, et al. Human intestinal lumen and mucosaassociated microbiota in patients with colorectal cancer. PloS One. 2012;7:e39743.

88. Wu N, Yang X, Zhang R, et al. Dysbiosis signature of fecal microbiota in colorectal cancer patients. Microb Ecol. 2013;66:462-470.

89. Klein RS, Recco RA, Catalano MT, et al. Association of Streptococcus bovis with carcinoma of the colon. N Engl J Med. 1977;297:800-802.

90. Seder CW, Kramer M, Long G, et al. Clostridium septicum aortitis: report of two cases and review of the literature. J Vasc Surg. 2009;49:13041309.

91. Toprak NU, Yagci A, Gulluoglu BM, et al. A possible role of Bacteroides fragilis enterotoxin in the aetiology of colorectal cancer. Clin Microbiol Infect. 2006;12:782-786.

92. Barthold SW, Jonas AM. Morphogenesis of early 1, 2-dimethylhydrazineinduced lesions and latent period reduction of colon carcinogenesis in mice by a variant of Citrobacter freundii. Cancer Res. 1977;37:43524360.

93. Balamurugan R, Rajendiran E, George $\mathrm{S}$, et al. Real-time polymerase chain reaction quantification of specific butyrate-producing bacteria, Desulfovibrio and Enterococcus faecalis in the feces of patients with colorectal cancer. J Gastroenterol Hepatol. 2008;23(8 Pt 1):1298-1303.

94. Martin HM, Campbell BJ, Hart CA, et al. Enhanced Escherichia coli adherence and invasion in Crohn's disease and colon cancer. Gastroenterology. 2004;127:80-93.

95. Bonnet M, Buc E, Sauvanet $P$, et al. Colonization of the human gut by E. coli and colorectal cancer risk. Clin Cancer Res. 2014:20:859-867.
96. Nagamine CM, Sohn JJ, Rickman BH, et al. Helicobacter hepaticus infection promotes colon tumorigenesis in the BALB/c-Rag2(-/-) Apc(Min/+) mouse. Infect Immun. 2008;76:2758-2766.

97. Maggio-Price L, Treuting P, Zeng WP, et al. Helicobacter infection is required for inflammation and colon cancer in SMAD3-deficient mice. Cancer Res. 2006;66:828-838.

98. Hale LP, Perera D, Gottfried MR, et al. Neonatal co-infection with helicobacter species markedly accelerates the development of inflammation-associated colonic neoplasia in IL-10(-/-) mice. Helicobacter. 2007;12:598-604.

Cite this article as: Coleman Ol, Nunes T (2016) Role of the microbiota in colorectal cancer: updates on microbial associations and therapeutic implications, BioResearch Open Access 5:1, 279-288, DOI: 10.1089/biores.2016.0028.

$\begin{aligned} & \text { Abbreviations Used } \\ \mathrm{AOM}= & \text { azoxymethane } \\ \mathrm{BFT} & =\text { Bacteroides fragilis toxin } \\ \mathrm{CAC} & =\text { colitis-associated cancer } \\ \mathrm{CRC} & =\text { colorectal cancer } \\ \mathrm{DSS} & =\text { dextran sodium sulfate } \\ \mathrm{ETBF} & =\text { enterotoxigenic Bacteroides fragilis } \\ \mathrm{HBV} & =\text { hepatitis } \mathrm{B} \text { virus } \\ \mathrm{HCA} & =\text { heterocyclic amine } \\ \mathrm{NF}-\kappa \mathrm{B} & =\text { nuclear factor } \kappa \mathrm{B} \\ \mathrm{OUT} & =\text { operational taxonomic units } \\ \mathrm{ROS} & =\text { reactive oxygen species } \\ \mathrm{SCFA} & =\text { short-chain fatty acid } \\ \mathrm{SMO} & =\text { spermine oxidase } \\ \mathrm{WT} & =\text { wild type }\end{aligned}$

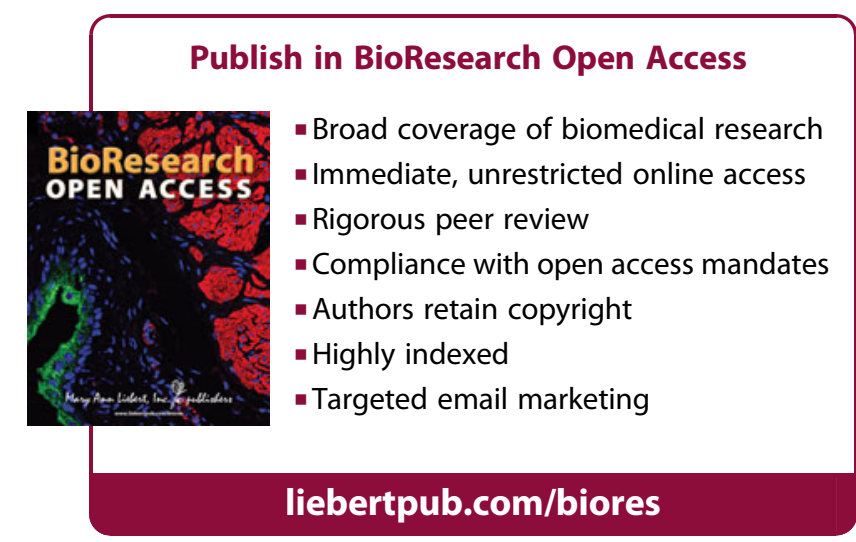

